\title{
The Scarring Effect of “Women's Work": The Determinants of Women's Attrition from Male-dominated Occupations
}

\author{
Margarita Torre \\ Universidad Carlos III de Madrid
}

\begin{abstract}
Women's entry into formerly male-dominated occupations has increased in recent decades, yet a significant outflow remains. This study examines the determinants of women's exits from male-dominated occupations, focusing on the effect of previous occupational trajectories. In particular, it hypothesizes that occupational trajectories in female-dominated occupations are often imbued with meanings and beliefs about the (in)appropriateness of the worker, which adversely affect women's integration and chances when they enter the male sector. Using the NLSY79 dataset, the study analyzes the job histories of women employed in the United States between 1979 and 2006. The results reveal a disproportionate risk of exit among newcomers from female-dominated occupations. Also, women who re-enter the male field are more likely to leave it again. Altogether, the findings challenge explanations based on deficiencies in the information available to women at the moment of hiring. The evidence points to the existence of a "scar effect" of previous work in the female field, which hinders women's opportunities in the male sector and ends up increasing the likelihood of exit.
\end{abstract}

Keywords: sex segregation, male-dominated occupations, female-dominated occupations, occupational trajectories, scar effect

Word count: 9990 (tables and figures excluded) 


\section{Introduction}

Women's entry into professional and managerial fields in the United States has been one of the most dramatic shifts in the sex composition of occupations in recent decades (Cotter, Hermsen, and Vanneman 2004; Cohen, Huffman, and Knauer 2009; Mandel 2012, 2013; Jacobs 1992). However, women's accelerated entry into male dominated jobs has failed to eradicate occupational segregation by gender. Despite the increasing female presence in male-dominated occupations levels of occupational segregation remain high: in 2009 some 50 percent of women in the United States would have had to change occupation for women to be distributed in the labor market in the same way as men (Hegewisch et al. 2010). This is in part because women continue to leave gender-atypical occupations at higher rates than their male counterparts (Jacobs 1989). Specifically, in the early 1980s, the "revolving doors" were shown to send back 10 out of every 11 women from male-dominated occupations (Jacobs 1989), and the proportion was still over two-thirds in the 1990s and 2000s (Author 2011).

Much scholarly attention has been devoted so far to documenting the significant obstacles that women encounter in male-dominated occupations, ranging from problems of acceptance and integration (Moore 1988; Kanter 1988; McPherson, Smith-Lovin, and Cook 2001; Maume 1999; Taylor 2010) to skills deficits (Kmec, McDonald, and Trimble 2010; Waite and Berryman 1986) and the impact of time demands on the reconciliation of family life and work (Jacobs and Gerson 2004; Perchesky 2008). Nevertheless, previous research has tended to neglect the relevance of women's previous occupational trajectories. To illustrate this point let us imagine two almost identical women, who have just started working in the same male-dominated occupation. They both have the same educational background and have the same years' work experience. The only difference between the two women is that one started her career in the 
male sector right after schooling, while the other did so only after a period of employment in female-dominated jobs. Are both women equally likely to continue working in the new occupation? Do they both face the same kinds of problems when entering a new maledominated occupation? Drawing on existing theories and empirical studies, I argue that the later-entrant to the male dominated sector faces a higher chance of attrition than the earlymover, despite their similarities. This is in part because women's work ${ }^{1}$ (Reskin and Hartman 1986; Spradley and Mann 1975) is imbued with meanings and beliefs about the appropriateness and worth, or lack of it, of the worker, which have a negative impact on women's integration and opportunities in the male sector. I introduce the notion of scar effect to summarize the penalties associated with time spent in female-dominated occupations for women's opportunities in male-dominated occupations. The scar effect is thus not inevitably inconsistent with earlier explanations of women's exits. Quite the opposite, it works by exacerbating one or other of the mechanisms mentioned in the existing literature, deepening the problems women face and hastening exit. However, it establishes a relevant variant by distinguishing between women formerly employed in the male sector and those transitioning from outside.

The empirical analysis uses the National Longitudinal Survey of Youth 1979 dataset (NLSY79) to examine the work histories of women employed in the United States between 1979 and 2006, including a specific analysis of women's mobility from male-dominated occupations over the course of their working lives. This analysis makes a theoretical as well as an empirical contribution to the existing literature. First, prior studies have neglected the potential impact of previous occupational trajectories on women's attrition from male-dominated occupations. They have also often failed to address differences in mobility patterns between groups of women according to their position in the labor market. By contrast, this study addresses all these 
points and provides a more comprehensive explanation of women's exits from male-dominated occupations.

The core finding in this paper is that transitioning from a female-dominated occupation significantly increases the probability of attrition from male-dominated occupations. In addition, previous episodes of employment in male-dominated occupations have a notably positive effect on the probability of a woman's exiting a male-dominated occupation, especially if she is employed in a high-status position. The concurrence of these results challenges explanations contending that women's attrition from male occupations is a means to correct existing mismatches in women's preferences resulting from women's lack of information at the moment of hiring (Kmec, McDonald, and Trimble 2010; Waite and Berryman 1986). The findings not only show that previous experience in male-dominated occupations fails to boost women's survival rates, but also that women returning to the male-field, who may therefore be assumed to know the score, are in fact the most likely to exit once again. All in all, evidence points to the existence of a scar effect of "female work", so that women's exits can be partly explained by newcomers' disadvantages with respect to both men and women employed in male-dominated occupations, mainly in the most prestigious occupations. Incumbents in maledominated occupations tend to penalize women arriving from outside the world of men's work, whose presence is seen as inappropriate or peculiar, over other women whose career paths converge with those of their male counterparts.

\section{The scar effect}

Most of the change in the composition of occupations came from women entering maledominated occupations, while the presence of men in typically female-dominated occupations accounts for only a small part of occupational integration (Cotter, Hermsen, and Vanneman 
2004; Cohen, Huffman, and Knauer 2009; Jacobs 1992). Increasing transfers from typical female to typical male occupations have been attributed to shifts in attitudes and values (Charles and Grusky 2004; Davis and Greenstein 2009), improvements in the institutional and legal systems (Hirsh 2009; Tomaskovic-Devey et al. 2006; Pettit and Hook 2009) and, above all, to increasing sex equality in U.S. educational achievement (England and Li 2006; Buchmann, DiPrete, and McDaniel 2008). In general, we can affirm that women have had more incentives than men to move into non-traditional activities because traditionally female jobs and occupations are still very undervalued (England 2010).

Paradoxically, women's accelerated entry into male dominated jobs has been accompanied by a significant volume of exits. Meanwhile, the persistent devaluation of traditionally female jobs (Levanon, England, and Allison 2009) makes women's exit from male-dominated jobs particularly intriguing. Where jobs in the male field offer higher pay and benefits, returning to female-dominated occupations adversely affects promotion opportunities (Rosenbaum 1985) and means going back to lower status and pay (Levanon, England, and Allison 2009; England et al. 1994; Glass 1990). More specifically, the NLSY data used in this paper show that a woman transitioning from a male- to female-dominated occupation will suffer an average 20 percent drop in her earnings if she was employed as a manager or a professional of some kind. The average wage cut for other workers, meanwhile, will still be in the region of 17 percent. In short, both men and women have strong pecuniary and non-pecuniary incentives to move towards male-dominated occupations (England 2010; Mandel 2012). Yet moving back into a femaledominated occupation rather challenges the logic of occupational attainment. Such outflows have attracted scholars' interest because combating the high exit rate of women from maledominated jobs would help to desegregate occupations (Jacobs 1989). 
A very significant body of research widely documents the significant obstacles to acceptance and integration women encounter after entering a male-dominated occupation. Exclusionary practices like homophile behavior (McPherson, Smith-Lovin, and Cook 2001; TomaskovicDevey 1993), homo-social reproduction (Moore 1988) and tokenism (Kanter 1977) hamper women's performance at work and make their promotion and progress relative to male counterparts more difficult, precipitating their exit from men's jobs (Reskin 1993; Kanter 1977; Cassirer and Reskin 2000; Davies-Netzely 1998). Interestingly, Taylor (2010) provides evidence that occupational category itself may drive workplace interaction even if the workplace is more sex balanced than the occupation. In this regard, Maume (1999) found that the percentage of males in an occupation positively influenced men's promotion chances, while the likelihood of women's leaving their jobs similarly increased with the percentage of males in the occupation. These findings highlight the benefits of simultaneously considering both the worker's own sex and the gender-composition of the occupation, instead of focusing exclusively on the job level.

Besides integration problems, some researchers argue that early socialization provides women with less information and training for traditionally male jobs. As a result, adult women have fewer performance-relevant skills for typically male tasks than their male counterparts, even when levels of educational attainment are the same (Reskin 1993). This training deficit increases the chance of error and poor performance by women employed in male sectors, and these mismatches may be corrected by occupational exit (Kmec, McDonald, and Trimble 2010; Waite and Berryman 1986). More recently, scholars have identified the increasing time demands of high-status occupations as a relevant factor pushing women to leave maledominated jobs. The working day is getting longer, potentially making it harder for workers to 
find a work-life balance (Cha 2010; Jacobs and Gerson 2004; Percheski 2008). In other words, women's investment in high-status occupations does not prevent them from abandoning them later.

This paper contributes to existing research by addressing occupational trajectories, a dimension that has been inadequately considered in the literature. Studies rarely consider how and when women end up working in a particular occupation (Jacobs 1989). Some women, for example, start their careers in the male field immediately after schooling. Others do so after a period of employment in female or neutral occupations. Are both women just as likely to continue working in a new male-dominated occupation? Grounded in previous theoretical and empirical research, I contend that the probability of leaving male-dominated occupations is somewhat higher among women transitioning from female occupations than for other women. The rationale behind this argument is that occupational backgrounds in the female-dominated sector are imbued with meanings and beliefs about low suitability and worth, which may hinder women's integration in male-dominated occupations more than other occupational paths. There can be no doubt that jobs in the female-dominated sector have all too often been seen as low status work for the weak (England 1992). Research reveals a general bias against women' work, which is reflected in different ways. Indeed, not only men, but also women themselves tend to assign more worth to work performed by men (Deaux 1985). In fact, much scholarly attention has been expended to show that skills related with women's work are systematically underrated (England et al. 1994; Jacobs and Steinberg 1990; Glass 1990) and recent research shows that female work is still persistently devalued (Mandel 2013; Levanon, England, and Allison 2009). I contend that this generalized belief about the inferiority of work in female-dominated occupations leads the dominant group to fear the potential loss of social status associated with 
the growing presence of socially devalued groups, and this may give existing personnel (both men and women) an incentive to hamper the integration of newcomers with the wrong background. In other words, time spent out of the male sector can raise doubts about entrants' legitimacy because of their occupational histories.

I use the term scar effect to refer to the penalty resulting from previous employment in femaledominated occupations. Most of the scarring literature has focused on the consequences of unemployment in developed countries, showing that prolonged exposure to unemployment has persistent negative effects on workers' subsequent careers (Gangl 2006; Arulampalam 2001; Ruhm 1991). In the context of the present study, the scar effect concerns a different course of events which might also affect intragenerational mobility processes. The scar effect, then, means that women's attrition from male-dominated occupations will be linked to the relative disadvantage of newcomers transitioning from female occupations with respect to incumbents, whether men or women, who will endeavor to hold onto their privileges. The scar effect is thus not inevitably incompatible with existing explanations of women's attrition. On the contrary, it can work by exacerbating one or other of the mechanisms mentioned, aggravating the problems women face and hastening their exit. However, it also establishes a relevant variant between women formerly employed in the male sector and those transitioning from outside. Consequently, the following will be observed:

H1. Women transitioning from the female sector are more likely to move out of male-dominated occupations

This differentiation between women on the basis of their occupational trajectories is a key departure from the conventional status characteristics theory, which claims that there is a 
positive relationship between the resources that a particular group possesses and the capability attributed to its members. Since women tend to hold positions with lower rank and less control over resources than men do, they are assumed to be worth less (Ridgeway et al. 1998). The notion of the scar effect overlaps the status characteristics theory insofar as both predict an imbalanced relationship between men and women in the male-dominated field. However, it diverges by adding a new dimension of inequality. While status characteristics theory assumes that women in male-dominated occupations are discriminated against merely for being women, the scar effect predicts that women arriving from the female-dominated field will be doubly disadvantaged with respect both to men and to other women previously employed in the maledominated field.

\section{Alternative explanations to the scar effect}

A different line of research has linked women's propensity to leave male-dominated occupations to information deficiencies at the hiring stage (Sousa-Poza and Henneberger 2002; Altman 2001; Becker 1965). According to this view, women may decide to enter male occupations under conditions of uncertainty, due to a lack of precise information about their new working conditions and work environment, resulting in mismatches when very real problems of integration, promotion and poor working conditions are encountered compared to the jobs they might conceivably take in the female-dominated sector. In other words, women opt to jump after evaluating the advantages and disadvantages of staying in male-dominated occupations. In this case, women's exits may be interpreted as a strategy to eliminate existing mismatches (Sousa-Poza and Henneberger 2002; Altman 2001; Becker 1965).

There are, then, two alternative explanations for the same empirical observation. Whether female attrition from male-dominated jobs is a response to poor information at the moment of 
hiring, or whether it is the result of integration problems and constraints, women transitioning from female occupations will be more likely to leave the male field again. Unfortunately, available data rarely allow testing for the specific social mechanisms explaining women's attrition from male-dominated occupations, making it difficult to disentangle competing explanations. To overcome this problem, I examine the effects of previous episodes of work in male-dominated occupations on women's occupational mobility.

If incomplete information is the main reason underlying women's exits, it might be expected that women who re-enter the male field would be less likely to leave it again. Certainly, women returning to the same or a similar occupation will have more specific information about tasks, duties and other occupational attributes than they had in the past. Furthermore, previous experience will provide women with broad information about male work environments, advantages and disadvantages of work within a male majority and other general features of working in the male sector. Thus, previous episodes of employment in male-dominated occupations endow women with both specific and general information which should have a negative effect on the probability that women will exit male-dominated occupations. Consequently:

H2. Previous experience in male-dominated occupations reduces the probability of moving out of male-dominated occupations.

Conversely, if there is a scar effect constraining women's chances and pushing them out of male occupations, there will be no reason to expect that previous experience in the male sector would reduce the probability of leaving. On the contrary, co-workers might also perceive previous 
episodes of attrition from male-dominated occupations as an indication of failure, or of women's inability to fulfill their responsibilities, raising the probability of exit. As a result, the alternative hypothesis (H20) would be observed.

To recap, simultaneous occurrence of $\mathrm{H} 1$ and $\mathrm{H} 2$ would support the information deficiency argument. If reentry in the male sector reduces the probability of subsequent exit, then occupational attrition could be understood as a way of fixing mismatches due to poor information at the moment of hiring. However, if $\mathrm{H} 1$ holds but $\mathrm{H} 2$ does not, this would support the scar effect scenario, suggesting that previous employment in female-dominated occupations may end up constraining women's opportunities in male-dominated occupations. Finally, results will be consistent with the status characteristics theory if neither of these two hypotheses is confirmed. Admittedly, available data do not allow identifying the specific social mechanisms underlying women's attrition from male-dominated occupations. Yet, by analyzing career dynamics, the present study provides a necessary first step for the empirical testing of these challenging explanations.

\section{Women's heterogeneity}

The prevalence of one or other of these scenarios might, however, be a function of women's relative position in the labor market. As shown in the literature, differences between high- and low-status workers can result in different patterns of mobility for a variety of reasons. On the one hand, the higher a person is on the occupational ladder, the fewer the options they have either for upward or sideways mobility (England 2010, 2011). Also, top occupations are defined by higher levels of investment in firm-specific and job-specific skills (Tam 1997), thereby increasing the costs associated with changing occupation. General skills, in contrast, are more 
frequently found in low-status occupations and are more easily transferable both from one job to another, and from male- to female-dominated occupations. Additionally, the opportunity cost (in terms of both loss of skills and income) per unit of time out of the labor market is considerably higher for well-educated, high status workers, and empirical evidence shows that highly qualified professional women return to work more quickly than their less well-qualified peers (England and Folbre 2005). Moreover, in the United States high-status workers can draw on significantly more resources than low-status workers when it comes to balancing work and family life. For example, highly skilled professional workers are either covered by the Family and Medical Leave Act (FMLA) or may already enjoy more generous employer-sponsored parental leave (Pettit and Hook 2009). Low-status workers, however, are not always covered by the FMLA and frequently cannot afford to take unpaid leave from work or pay for private childcare (Pettit and Hook 2009; Gerstel and McGonagle 1999). Taking all this into account, managerial and professional workers seem to be less likely than other lower-status workers to move out of male-dominated occupations. However, high status workers are expected to be more susceptible to potential penalty effects, mainly for two reasons. First, opportunities narrow at the top of the occupational structure, increasing competition and rivalry. And second, the ability of incumbents to exclude newcomers depends on their own power, including job tenure (Reskin and Roos 1990). Thus, we may expect the scar effect scenario to be more likely among women at the top of the occupational ladder. Consequently:

H3. The scar effect scenario is more likely to be found among high-status workers

\section{Data}


The main source of data for this analysis is the NLSY79 survey, which consists of data on a nationally representative sample of 3,108 young women and 3,003 young men in the civilian population who were born in the 1950s or 1960s. They were first surveyed in 1979, interviewed annually until 1994, and biannually after that. The period analyzed here runs from 1979 to 2006. I decided to end the analysis in 2006 in order to avoid noise derived from the subsequent global economic turbulence, which might confuse the results. Respondents were asked about their current market situation (e.g. employment status, current occupation, job tenure) in each wave of the NLSY79, and their experiences over the previous calendar year (e.g. hours worked, earnings). This provides an idea of the nature of career transitions. Although a primary focus of the NLSY79 survey is labor force behavior, it has a much broader scope, including detailed questions on educational attainment, investment in training, and marital and fertility histories. Additional labor force information includes hours worked, earnings, occupation, industry, benefits and other specific job characteristics.

Year-on-year attrition rates for respondents in the NLSY79 are low. Indeed, cumulative retention rates were over 90 percent in the first half of the period considered here, dropping to around 78 percent by the end. Individuals' work histories are analyzed for the first time two years after the individual left school. This cut-off point is intended to minimize the statistical noise produced by the large number of temporary jobs taken and unstructured mobility experienced during the education period and early years of employment (Clark and Summers $1982)^{2}$. The whole job history of individuals who did not report enrollment in education in either of the two first waves is considered, however. 
Appended to the NLSY79 is the sex composition of three-digit census occupations for 1980, 1990 and 2000. Census codes are standardized and expressed in the 1990 three-digit occupational codes, to make them comparable over time ${ }^{3}$.

\section{Methods and covariates}

A discrete-time hazard model is used to model career experiences, given that the exact timing of job transitions is unknown (Allison 1984). The strategy in this kind of event history analysis is to estimate the conditional probability $\left(\mathrm{P}_{\mathrm{it}}\right)$ that individual $i$ will experience an event at time $t$, given that the individual has not already undergone such an occurrence it the past. The event analyzed is a career move from a male-dominated occupation, which is analyzed in a two-step procedure. First, the probability of moving within male-dominated jobs is estimated. After that, the second model estimates the probability of exit to a typically female job.

Occupations are classified as male-dominated when female presence in the occupation runs at below 33.3 percent and female-dominated if women's representation is 66.6 percent or above ${ }^{4}$. All others are gender-neutral. While the same female cut-off point percentage is used throughout the study, it would be wrong to assume that an occupation classified as maledominated in 1979 was still male-dominated in 2006. To account for the shifting sex composition of occupations I have updated the classification every 10 years, using census data from the closest decade ${ }^{5-6}$. For each employment spell, the sex composition of the occupation is kept constant. In other words, if a woman started a job in 1982, her occupation is assigned the 1980 sex composition rating, even if she stays in the same occupation for 20 years. Similarly, if she started an occupational episode in 1995, her occupation is assigned the 1990 sex composition rating. Thus, the most appropriate occupational data is assigned to each 
employment experience, but the occupational sex composition remains the same for each experience.

Women were tracked from the moment they started working in a male-dominated occupation until they experienced a career transition. Thus, respondents excluded from the initial sample in 1979 (i.e., non-working respondents or those working in a non-male dominated occupation) could enter the risk set in later years. If repeated events are observed, the clock is reset to 0 each time the individual enters the risk set, and the intervals between events are treated as distinct observations (Allison 1995). Consequently, if a woman takes a job in a male-dominated occupation three times over the observation period, three observations will be created. Conversely, if a woman does not reenter the male-dominated field after a career transition, she is no longer in the risk set. The sample includes a total of 3,067 women. The sum of personyears in the pooled data set from 1979 to 2006 was 10,289, of which 5,295 relate to women working as professionals or managers, and the remaining 4,994 to women in other occupations. Detailed person-year figures are presented in Table 1, given that the number of cases contributing to the pooled data set may vary each year.

(Table 1 about here)

Analysis of repeated events has the advantage of providing more statistical power (Allison 1995). However, whenever there are multiple observations per individual, there is also likely to be statistical dependence between observations. To correct for dependence derived from repeated events, I calculated robust standard errors (Allison 1995) ${ }^{7}$. Finally, possible heterogeneity among groups of women (H3) is taken into account by running separate 
regressions for managers and professionals on the one hand, and for other working women on the other. Controls for major occupational groups are added to capture possible inter-group differences.

The probability $P_{i t}$ defined above is related to the covariate vectors by a logistic regression equation, which can be specified as follows:

(1) $\left.\log \frac{P_{i t}}{1-P_{i t}}\right)=\alpha+\beta X_{i t}+\gamma Z_{i t}+\delta W_{i t}$

Xit, Zit and Wit are vectors of explanatory variables observed for individual $i$ at time $t$ (although some of the variables in the vector may not vary with time). More specifically, the vector $X i$ is a vector of socio-demographic variables, which includes measures for education, marital status and maternity status. Two different variables are included for education, consisting of a dummy variable for educational attainment (college or more vs. less than college) and field of study. This latter is labeled male-dominated major, and scores 1 for those women who studied a typically male major (i.e. those with a male presence of 66 percent or over) and 0 otherwise ${ }^{8}$. Finally, attending school after entry in the labor market controls for subsequent re-entries to the school system, and is scored as 1 when the individual is attending school and 0 otherwise.

Changes in marital status are captured through dummy variables (getting married and marriage dissolution). Also, controls for first born and second born are introduced, together with the variable mother's age at first child. The purpose of this variable is to control for possible endogenous relationships between job trajectory and maternity preferences. Women working in top-ranking positions are more likely than other female workers to remain childless, or to 
delay having their first child until they are older, which may stimulate interests that compete with fulfillment of their parental role (Kohler, Billari, and Ortega 2002).

Vector $\mathrm{Z} i$ is composed of work-related variables, such as working full-time (vs. part-time) and occupational categories, namely managers, professionals (non-teachers), teachers, and service, clerical, sales and blue-collar workers. Given the proliferation of managerial categories between 1970 and 1980 (Jacobs 1992), however, important differences between women within the same occupational category will probably not be fully captured by the three-digit census occupations. In order to take account of this potential heterogeneity in managerial categories, I have redistributed managers into three sub-categories according to their individual hourly rate of pay relative to the average hourly rate of pay in their occupation (both weighted by year and job tenure). Women whose hourly rate of pay is in the 75 percentile and above are classified as high-paid managers. Those whose hourly rate of pay is equal to or below the 25 percentile are classified as low-paid managers. All the rest are defined as mid-paid managers.

The $W i$ vector complements the two described above with a set of variables that identify an occupational trajectory from the time that a woman first leaves the education system. Occupational trajectories are captured by different indicators, namely, work leaves in the previous year, years of experience in the labor market, number of job spells, years spent out of the labor market, job tenure and job tenure squared. These variables measure whether mobility is related to accumulated experience and allow observing whether attrition is higher among more mobile individuals. Finally, the main interest of this study lies in the variables last occupation: female-dominated and number of previous episodes in/exits from male-dominated occupations. These indicators are meant to measure the sex-composition of the previous 
occupation and previous work experiences in the male-dominated field. Both variables are combined to test $\mathrm{H} 1$ and $\mathrm{H} 2$, and to discriminate among alternative explanations.

Finally, the variable period, which scores 0 when the event occurs before 1990 and 1 otherwise, is included to take account of possible changes in the occupational structure, which could affect mobility patterns (such as the increase in the number of female-oriented occupations over time). According to census data $(1980,1990,2000)$, the number of female-dominated managerial occupations before 1990 was virtually nil, and it was only in this decade that they began to emerge. Additionally, the period variable controls for potential variations resulting from changes made to the coding system in the early $90 \mathrm{~s}^{9}$. Other factors like job tenure and age of entry into the labor market are included as control variables. Table 2 summarizes the main descriptive statistics for the variables.

(Table 2 about here)

\section{Findings}

\section{Mobility in the sample}

Evidence for the "revolving door" phenomenon described by Jacobs (1989) is found in the NLSY79 sample. Figure 1 shows the person-year flows for women between male-dominated, female-dominated and neutral occupations for the entire period 1979-2006. According to the top of the panel, a total of 1,853 female transitions from female- to male-dominated occupations are observed, which is 15.92 percent of women's total mobility in the female-sector. The number of exits in the opposite direction is 1,764 , accounting for 42.11 percent of women's 
occupational changes in the male sector. Interestingly, female turnover in male-dominated jobs is relatively recurrent. Contrary to the frequent assumption found in the literature, almost 33 percent of women professionals and managers, and 23 percent of women in other occupational categories, move into a male-dominated occupation at least twice in their working lives.

The bottom of the panel reflects the breakdown based on the occupational category of origin. As mentioned in the discussion of women's heterogeneity, different patterns of mobility among high- and low-status workers are observable at first glance. For example, transitions from female- to male-dominated occupations represent about a 10.48 percent of the total occupational moves made by managers and professionals starting in female-dominated occupations. This percentage increases by almost 6 points for other workers. Remarkably, the opposite trend is observed among women leaving the male field. Specifically, high-status workers moving from male- towards female-dominated occupations account for 45.99 percent, nearly the half of all the occupational moves originating in the male field. This exceeds the figure for low-status workers by almost 10 points.

(Figure 1 about here)

Women are concentrated in fewer occupations than men, as has been the case for decades (Cotter, Hermsen, and Vanneman 2004; Reskin and Roos 1990; Jacobs 1989). We find women working in 172 of the 206 occupations classified as male-dominated. However, women are fairly evenly distributed across high-status occupations (51.70 percent) and low-status occupations (48.30 percent). Specifically, female managers and professionals are spread over 55 of the 62 occupational titles in our sample. Attrition is observed from 41 of these male 
occupations, principally: "Managers and administrators, n.e.c.", "Managers, marketing, advertising and publicity", "Lawyers", and "Computer systems analyst and scientist". Upon leaving male-dominated jobs, less than 10 percent obtain a management position in the female field, such as "Managers, medicine and heath" (with a 68 percent of female presence). Mediumand low-paid managers and professional workers mostly become "Secretaries" (15.12 percent) and occupy "Administrative support occupations" (7.95 percent). About 3.3 percent continue to work as managers after a job change.

The female presence in other occupational categories is spread across 117 of the total 144 maledominated jobs. Attrition to female-dominated occupations is observable from at least 77 of these occupations, in particular: "Machine operators, not specified", "Stock handlers and baggers", "Janitors and cleaners", "Laborers, except construction", and "Traffic, shipping and receiving clerks". After changing occupations, women were most often classified as "Cashiers" (11.27 percent); “Housekeepers and Butlers" (10.48 percent); "Secretaries" (6.42 percent); and "Sales workers, other commodities" (5.64 percent).

In all the cases, transitions entail variations ranging from 33 to 73 percent in the proportion of females in the occupation of origin and destination. This significant difference in the sexcomposition of occupations translates into differences in other occupation-related attributes, which are unequally distributed across male- and female-dominated occupations. To clarify this point, let us compare two of the occupations above: "Janitors and cleaners", with a 31 percent female presence and "Housekeepers and Butlers", in which the proportion of women is as high as 93 percent. Despite their apparent similarity, the truth is that these occupations are quite different. Beyond the significant number of women employed in each of these occupations, they 
have different hourly wages, tasks, abilities, and work environments. For example, according to the Occupational Information Network database ${ }^{10}$, janitors' and cleaners' wages are higher than housekeepers' and butlers'. Also, janitorial and cleaning duties may include heavy work (e.g. washing walls and windows, removing rubbish, tending furnaces and boilers, clearing snow or debris from sidewalks) while the housekeepers and butlers perform a combination of light cleaning duties like making beds, replenishing linens, cleaning rooms and halls, and vacuuming.

These data reveal that mobility has different consequences for women working in professional and non-professional sectors, those in the first group being more likely to experience a decline in occupational status when moving into the female sector (Levanon, England and Allison 2009; Mandel 2012). This fact clearly challenges the idea that job mobility is linked to the process of occupational attainment as "generated by the individual to maximize status and income" (Sorensen 1974). The next section takes a more detailed look at the determinants of mobility in and across gender boundaries.

\section{Multivariate analysis}

Table 3 shows the odds ratio produced for the discrete-time hazard model for professionals and managerial workers.

(Table 3 about here)

The first difference observed relates to the effect of the sex composition of college majors. Thus, women with a male-dominated major are more likely to change occupations within the male sector, while they are significantly less likely to move to female-dominated occupations. 
This result indicates the relevance of appropriate skills and training in explaining attrition from male jobs.

Another significant difference emerges with regard to work and family issues. On the one hand, the probability of changing occupations within the male field does not vary with changes in marital status and births. On the contrary, both marriage and divorce increase the likelihood of moving towards female-dominated occupations. However, it is not easy to link these results to increases in family responsibilities, as other variables measuring the potential conflict between work and family do not have a clear impact on women's exit from male-dominated jobs. For example, the birth of a first or second child does not explain why women move to femaledominated occupations, and neither does the mother's age at the time of the first birth. In addition, the full-time work variable in fact significantly reduces the probability of leaving, suggesting that exits cannot be interpreted as female willingness to work part-time. All in all, these results are inconsistent with the human capital expectation that women leave to take female jobs which offer greater flexibility and ease of work, and allow them to fulfill their dual obligations as employees and homemakers (Becker 1965). However, they are in line with studies claiming that the higher pay and better benefits of male-dominated jobs are generally more attractive to women who have families to support (Padavic 1992). Moreover, although female occupations are frequently part-time, job characteristics that are supposed to facilitate child-rearing, such as flexible working hours, are actually more common in typically male jobs than in female jobs (Glass 1990).

Consistent with the proliferation of managerial titles in the 70s and 80s (Jacobs 1992), mid- and low-rank managers are more likely than professionals to experience attrition to female 
occupations. The high-paid managers' category, on the other hand, does not show a significant effect. Leaving aside the level of significance, however, the coefficient takes the same sign as for the other categories; hence being a high-paid manager is positively related to departures towards female-dominated jobs but negatively associated with moves within male-dominated occupations.

The most revealing findings concern the third block of variables. The variable last occupation: female-dominated shows that newcomers from non-male dominated occupations are more likely to leave again, and at the same time they are less likely to move within male occupations. To be precise, the probability of changing within male occupations is about 70 percent lower in the case of new arrivals, all other things being equal. Conversely, newcomers are 2.3 times more likely to move back into a female-dominated job, confirming H1. On the face of it, this might suggest that after a period of evaluation, women are more likely to transition to jobs with a similar sex composition to their last job, and into jobs of a similar kind. However, this idea is hard to reconcile with the effect of previous episodes in/exits from male-dominated occupations, which also increases the probability of further exits from the male sector. The fact that women who have worked in the male field in the past show a higher probability of leaving than those employed for the first time corroborates $\mathrm{H} 2$ and challenges the supposition that women's attrition from male-dominated jobs is due to poor information at the point of hiring. In fact, the simultaneous significant and positive effects of these two coefficients validates the thesis that women arriving from female-dominated occupations do in fact suffer a scar effect, which increases the difficulties they face in male-dominated occupations and precipitates their exit. 
Table 4 shows the results for service, clerical and blue-collar female workers. As in the case of professionals, mobility patterns vary according to the end occupation, although the experience of low-status workers is marked by a number of interesting features. For example, individual attributes do not seem to be related to mobility in one direction or another. More specifically, the effects of field of study and marital status vanish for low-status workers. Nevertheless, differences emerge between full-time and part-time employees, the former being less likely to move towards female-dominated occupations. Here again, women's attrition towards the female field cannot be easily linked to women's desire to facilitate the conciliation of both work and family responsibilities.

Interestingly, the results confirm the relevance of the main variable of interest. Once again, results support $\mathrm{H} 1$ as newcomers are 1.61 times more likely to abandon a male-dominated occupation, and about 50 percent less likely to change jobs within the same sector. Moreover, prior episodes in/exits from male-dominated occupations does not have any effect on the risk of attrition among non-professional women. Here again, the confirmation of $\mathrm{H} 1$ and $\mathrm{H} 2$ corroborates the scar effect approach. However, there is no additional penalty associated with previous attrition experiences, in contrast to high-status workers. In other words, the empirical evidence supports the existence of a scar effect that is indeed less pronounced among low-status workers, as predicted in $\mathrm{H} 3$. On the one hand, both professionals and managers generally have more power and enjoy greater opportunities to take part, whether formally and informally, in decisions affecting other workers. Furthermore, it is at the top of the occupational ladder where rivalry is most likely to emerge given the scarcity of positions. All these reasons would help to explain the observed differences among high- and low-status workers. 
Finally, the variable period is not significant, indicating that sex-typed mobility is not simply a by-product of variations in the occupational structure, or of changes in the codification system made in the 1990s.

(Table 4 about here)

Taken as a whole, these results confirm that survival in male-dominated occupations is closely bound up with women's labor market trajectories, although it varies depending on their occupational status. This effect is clearly observable in Figure 2, which illustrates the probability of female job attrition in the first five years of employment in a male-dominated occupation. The graph on the left shows the results for high-status workers and the one on the right for low-status workers. More specifically, the data refer to professionals (non-teachers) and blue-collar workers, respectively, as they are both the largest groups and also the most stable according to the results reported above. In both cases, the scenario is highly unfavorable for attrition ${ }^{11}$, so graphs show the lowest predicted probabilities of change to a female occupation.

(Figure 2 about here)

Under these conditions, Figure 2 shows the probability of moving into a female-dominated occupation for professionals (left) and blue-collar workers (right). The continuous line shows the probability of attrition for women who arrived in their occupation from within the male sector (i.e. insiders). In line with predictions, the probability of leaving after one year is lower for professionals (under 25 percent) than it is for blue-collar workers (about 30 percent). The dashed line represents the probability of exit for newcomers. In both graphs we may observe an 
increase in the likelihood of exit in comparison to insiders, and as expected the increase is higher for professionals than for blue-collar workers. In particular, the probability of attrition to female occupations rises from 24 percent for insiders to over 40 percent for newcomers in the case of professionals. The increase for blue-collar workers is more moderate, rising from 30 to 40 points. Finally, the dashed-dot line shows the probability of exit for newcomers who have previous episodes of employment in male-dominated occupations. In the case of professionals, the probability of exit raises still further, to about 50 percent, almost twice the probability of attrition for insiders. No changes associated with early episodes in male-dominated occupations are observable among blue-collar workers. In short, the probability of attrition is substantially higher for newcomers than for insiders among both categories of workers, while professionals suffer extra penalties for earlier episodes of attrition.

The findings presented here show that women's attrition from male-dominated occupations is the result of combinations of individual, work and career-history factors. The results corroborate the significance of women's work trajectories for their continuity in maledominated occupations. Specifically, a two-sided effect is observed. In the short-term, newcomers to a male occupation face a higher risk of attrition to a female occupation. In the long-term, penalties are also identifiable, as previous episodes of employment in maledominated jobs not only do not reduce the probability of exit, but they in fact increase it. However, this holds only for professionals and managers, which is to say the women holding the most desirable jobs. Thus, poor information does not seem to offer a convincing explanation for women's exits, because prior experience does not reduce the likelihood of exit. Both results indicate the existence of a scar effect resulting from time spent out of the male-dominated field. 
All in all, women's access to typical male occupations does not guarantee their survival in a male-dominated sector, as women continue to face barriers after the hiring stage.

\section{Discussion}

The entry of women into traditionally male occupations has intensified in recent decades, but outflows still remain significant. Identifying the reasons why women continue to leave traditional male occupations is important because cutting the high rate at which women leave male-dominated jobs could substantially reduce the level of occupational segregation by sex. Building on leading explanations, this study has examined the role of previous occupational trajectories on the probability of women's attrition from male-dominated occupations. More specifically, it argued that occupational trajectories in the female field are filled with meanings and beliefs about the (in)appropriateness of the worker, which adversely affect women's integration and chances when they enter the male sector. I have coined the term scar effect to refer to the disadvantages experienced by women transitioning from the female sector.

The scar effect premise was tested together with alternative explanations using NLSY79 data. Findings reveal a disproportionate risk of attrition among female newcomers to male-dominated occupations from female occupations. Also, all else being equal, those women who re-enter (and are therefore better informed) are in fact more likely to leave again. Altogether, empirical evidence is hard to reconcile with alternative theories based on deficiencies in the information available to women at the moment of hiring. The findings in fact point in the opposite direction, supporting the idea that previous employment in the female-dominated field hinders women's opportunities in the male sector. In other words, there is a scarring effect of women's work - 
which inspires the title of this paper- that ends up increasing the likelihood of attrition. This is especially true among professional and managerial workers, given that at the top of the occupational ladder the scarcity of positions becomes more evident and rivalry is most likely to emerge. The existence of a scar effect has broad implications for scholarship on labor market segregation.

First, the scar effect explanation overlaps conventional social status theory in many ways, but it also establishes a new dimension of inequality by distinguishing between women formerly employed in the male sector and those transitioning from outside. In other words, the scar effect approach emphasizes a conflict of interest between insiders and outsiders above and beyond the gendered dimension of inequality. Findings suggest that incumbents in male-dominated occupations tend to penalize women arriving from outside the world of men's work, whose presence is seen as inappropriate or peculiar, more than other women whose career paths converge with those of their male counterparts. In fact, women who started their careers in the male sector have a higher probability of remaining in it. However, those who decide to leave for a period for whatever personal or professional reasons will encounter serious difficulties if they try to come back. All in all, it seems that women seeking to make a career in a maledominated sector are implicitly required to follow conventional male career patterns. To echo England (2010), changes in the labor market are gender asymmetric, and women's lives have changed much more than men's in recent decades. In this light, it appears that women's access to traditional male jobs is not enough to guarantee a reduction in the level of segregation in the job market. Despite their ability to 'unlock the door' to male occupations, women continue to face barriers after the hiring stage. Access without support is not opportunity. 
The results of this study also contributes to recent literature in showing increasing differentiation between types of occupational groups, as high- and low-status workers display clearly divergent mobility patterns. Indeed, recent studies have emphasized that upward occupational mobility among women is largely due to access by managerial and professional workers to male-dominated, highly paid occupations (England 2010; Mandel 2012). The present findings reveal that women employed at the top of the occupational ladder are more likely to pay a price for time spent in female sectors, however impressive their achievements.

Existing research implicitly assumes exit from a male-dominated occupation to be a one-off event in a woman's life. In actual fact, however, women may be employed in the male sector at different times (Jacobs 1989), and each of these experiences is not inevitably the same as the previous one, or the next. As the results show, previous work trajectories must be considered if we are to arrive at a fuller understanding of women's behavior in the male sector, and both the occupation of origin and destination must be accounted for to obtain a clear picture of mobility patterns. Indeed, the use of new indicators in this work provides fresh insights into the processes of attrition from male- to female-dominated occupations and represents a necessary first step in laying bare the impact of previous occupational paths. However, the empirical findings obtained from this study raise new questions that will require further research. The impact of other factors which are not considered in this study may be relevant to understanding women's occupational transitions. For example, moves into female occupations might also depend on the existence of specific network facilitating the change in sector. Also, further research will need to account for the potential role of occupational attributes in women's exits into the female field. Thus, detailed data on social networks and occupational features will help advance our understanding of the social mechanisms operating behind the exit of newcomers from male-dominated occupations. 
Finally, there is room here for a brief mention of male occupational trajectories. Men's mobility patterns differ substantially from women's. First, in line with previous findings (England 2010), I found that the number of men employed in sex atypical occupations is about the half that of woman. More precisely, while 10,239 women worked spells in male-dominated jobs, the number of men in female occupations was just 6,148 . Second, the number of men making the transition from male- to female-dominated occupations represented less than 3.5 percent of the total male mobility rate. In fact, about a 90 percent of men stay largely within male-dominated occupations and some 6.5 percent move into sex neutral occupations or withdraw from the labor market altogether. Finally, unlike women working in sex-atypical occupations, men are fairly unevenly distributed across high-status occupations (20 percent) and low-status occupations (80 percent). Moreover, they are concentrated in just a few female occupations. Specifically, more than half of male professionals and managers work as "Teachers, elementary school" (19 percent), "Social workers" (13 percent), "Managers, medicine and health" (11 percent) and "Health technologies and technicians" (8 percent). Among low-status workers, men were most often classified as "Sales workers" (31 percent), "Kitchen workers, food preparation" (6 percent) and "Investigator and adjustors" (6 percent). Interestingly, all of these occupations (with the sole exception of "Kitchen workers, food preparation") exceed the average wage of female-dominated occupations. Given all this, men's mobility patterns differ from women's in magnitude and characteristics. Further investigation is required to explain the mechanisms and motivations underlying men's mobility trends, and to account for the differences between men's and women's occupational trajectories in sex-atypical occupations.

\section{Endnotes}


1 Women's work is a term used to indicate work traditionally and historically undertaken by women. It was said to be an extension of mother/wife roles.

2 After this cut-off temporary employment is not expected to affect results. First, temporary jobs - as well as other forms of non-standard employment- are shown to be mainly steppingstones to permanent jobs once individuals acquire skills and experience (Booth, Francesconi and Frank 2002; Clark and Summers 1982). Second, professional childcare and the availability of part-time jobs have allowed women to work in periods like school vacations, when they formerly left the labor force (Ryzdweski et al. 1993). Finally, men and women are highly concentrated in different occupations within nonstandard employment arrangements (Kalleberg et al. 1997). Consequently, moving from one temporary job to another is more likely to happen within sex-type occupations than across sex-type boundaries.

3 Individuals move, but occupation changes between the 1980 and 1990 census categories were relatively minor, while the changes between 1990 and 2000 were more substantial. All of the data were reclassified based on 1990 occupational categories in order to determine whether any of the changes observed might be due to changes in occupational coding rather than changes in women's behavior. The results did not differ substantially using the recoded data.

4 Three equal-frequency categories were used to make results comparable with previous findings (Jacobs 1989). Results remain robust using other classification schemes (i.e, defining gender neutral within a narrower band $-45 \%$ to $55 \%$ ).

5 Occupations in 1979 are classified using 1980 census data.

6 When the analysis was replicated holding the sex composition of occupations constant over time, correlations between variables were found ranging from .97 to .99 .

7 Dependence among observations can be thought of as arising from unobserved heterogeneity, which could lead to artificially declining hazard functions and coefficients that tend towards 0 
(Allison 1995 1984, Blossfeld, Golsch and Rohwer 2007). A fixed-effect approach should correct some or all of the bias in the coefficients caused by unobserved heterogeneity. However, a fixed-effect model is not the preferred technique here for various reasons. First, it can only estimate coefficients for time-varying covariates. Second, the fixed-effect method does not perform well when the number of previous events is included as a covariate (Allison 1995), which is a key variable in this research. Additionally, it significantly reduces the number of observations as it excludes those women with only a single censored spell, as well as those with one censored spell and one uncensored spell, if the former is shorter than the latter.

8 The NLSY includes a question about the job position that women expect to hold in the future. However, this question was only asked in a few of the early surveys and was then removed from the questionnaire. This variable was not used, as preferences are not necessarily fixed over time. 9 Dependent coding was introduced in 1994 in order to reduce the interview burden and the possibility of misclassification.

10 The O*NET program is the primary US source of occupational information, containing information on hundreds of standardized and occupation-specific descriptors.

11 Full-time workers. The remaining dummy variables (except college degree for the professional group) are set at 0 and continuous variables at their mean.

\section{References}

Allison, Paul D. 1984. Event History Analysis: Regression for Longitudinal Event Data. Iowa City: Sage Publications.

1995. Survival Analysis using SAS: A Practical Guide. Cary, NC: SAS Institute. 
Arulampalam, Wiji. 2001. "Is Unemployment Really Scarring? Effects of Unemployment Experiences on Wages" Economic Journal 81:F585-F604

Becker, Gary S. 1965. "A Theory of the Allocation of Time." Economic Journal 75(299):493517.

Blossfeld, Hans-Peter, Katrin S. Golsch and Götz Rohwer. 2007. Event History Analysis with Stata. United States: Lawrence Erlbaum Associates Inc.

Booth, Alison L., Marco Francesconi and Jeff Frank. 2002. "Temporary Jobs: Stepping Stones Or Dead Ends?” Economic Journal 112:F189-F21

Buchmann, Claudia, Thomas A. DiPetre and Anne McDaniel. "Gender Inequalities in Education." Annual Review of Sociology 34:319-337.

Cassirer, Naomi and Barbara Reskin. 2000. "High Hopes: Organizational Location, Employment Experiences and Women's and Men's Promotion Aspirations." Work and Occupations 27(4):438-463.

Cha, Youngjoo. 2010. "Reinforcing Separate Spheres: The Effect of Spousal Overwork on Men's and Women's Employment in Dual-Earner Households.” American Sociological Review 75(2): 303-329

Charles, Maria and David B. Grusky. 2004. Occupational Ghettos. The World Wide Segregation of Women and Men. Stanford University Press. 
Clark, Kim B. and Lawrence H. Summers. 1982. "The Dynamics of youth unemployment” Pp. 199-234 in The Youth Labor Market Problem: Its Nature, Causes, and Consequences., edited by Richard B. Freeman and David A. Wise. University of Chicago Press.

Cohen, Phillip N., Matt L. Huffman and Stephanie Knauer. 2009. "Stalled Progress? Gender Segregation and Wage Inequality among American Managers, 1980-2000." Work \& Occupations 36:318-342.

Cotter, David A., Joan M. Hermsen and Reeve Vanneman. 2004. Gender Inequality at Work. New York: Russell Sage Foundation.

Davies-Netzely, Sally A. 1998. "Women Above the Glass Ceiling: Perceptions on Corporate Mobility and Strategies for Success." Gender and Society 12(3):339-355.

Davis, Shannon N. and Theodore N. Greenstein. 2009. "Gender Ideology: Components, Predictors, and Consequences." Annual Review of Sociology 35:87-105.

Deaux, Kay. 1985. "Sex and gender.” Annual Review of Psychology 36: 49-81.

England, Paula. 1992. Comparable Worth: Theories and Evidence. New York: Adline the Gruyter. Retrieved Book, Whole.

England, Paula. 2010. "The Gender Revolution: Uneven and Stalled." Gender and Society 24(2):149-166.

2011. "Reassessing the Uneven Gender Revolution and its Slowdown." Gender and Society 25(1):113-124. 
England, Paula, Melissa S. Herbert, Barbara S. Kilbourne, Lory L. Reid and Lory M. Megdal. 1994. "The Gendered Valuation of Occupations and Skills: Earnings in 1980 Census Occupations." Social Forces 73(1):65-100.

England, Paula and Nancy Folbre. 2005. "Gender and Economic Sociology." Pp. 627-649 in Handbook of Economic Sociology., edited by N.J. Smelser and R. Swedberg. New York: Russel Sage Foundation.

England, Paula and Su Li. 2006. "Desegregation Stalled: The Changing Gender Composition of College Majors, 1971-2002." Gender and Society 20:657-677.

Gangl, Markus. 2006. "Scar Effect of Unemployment: An assessment of Institutional Complementarities.” American Sociological Review 71:896-1013

Gerstel, Naomi and Katherine McGonagle. 1999. "Job Leaves and the Limits of the Family and Medical Leave Act: The Effects of Gender, Race, and Family." Work and Occupations 26(4):510-534.

Glass, Jennifer. 1990. "The Effect of Occupational Segregation on Working Conditions." Social Forces 68(3):779-796.

Hegewisch, Ariane, Hannah Liepman, Jeff Hayes and Heidi Hartmann. 2010. "Separate and Not Equal? Gender Segregation in the Labor Market and the Gender Wage Gap." Institute for Women's Policy Research Briefing Paper IWPR C377 (www.iwpr.org).

Hirsh, C. E. 2009. "The Strength of Weak Enforcement: The Impact of Discrimination Charges on Sex and Race Segregation in the Workplace." American Sociological Review 74(2):254271. 
Jacobs, Jerry A. 1989. Revolving Doors. Sex Segregation and Women's Careers. Stanford, California: Stanford University Press.

-----. 1992. "Women's Entry into Management: Trends in Earnings, Authority, and Values among Salaried Managers." Administrative Science Quarterly 37(2):282-301.

Jacobs, Jerry A. and Ronnie J. Steinberg. 1990. "Compensating Differentials and the MaleFemale Wage Gap: Evidence from the New York State Comparable Worth Study." Social Forces 69(2):439-468.

Jacobs, Jerry A. and Kathleen Gerson. 2004. The Time Divide: Work, Family and Gender Inequality. Harvard University Press.

Kalleberg, Arne L., Barbara Reskin and Ken Hudson. 2000. “ Bad Jobs in America: Standard and Nonstandard Employment Relations and Job Quality in the United States”. American Sociological Review, 65:256-278

Kanter, Rosabeth M. 1977. Men and Women of the Corporation. New York: Basic Books.

Kmec, Julie A., Steve McDonald and Lindsey B. Trimble. 2010. "Employment and the Nonsearch Process Making Gender Fit and "Correcting" Gender Misfits: Sex Segregated." Gender and Society 24(2):213-236.

Kohler, Hans-Peter, Francesco C. Billari and José A. Ortega. 2002. "The Emergence of LowestLow Fertility in Europe during the 1990s." Population and Development Review 28(4):641-680. 
Levanon, Asaf, Paula England and Paul D. Allison. 2009. "Occupational Feminization and Pay: Assessing Causal Dynamics using 1950-2000 Census Data." Social Forces 88:497-517.

Mandel, Hadas. 2012. "Occupational Mobility of American Women: Compositional and Structural Changes, 1980-2007." Research in Social Stratification and Mobility:5-6.

-----. 2013. “Up the Down Staircase: Women's Upward Mobility and the Wage Penalty for Occupational Feminization, 1970-2007’. Social Forces 91 (4): 1183-1207.

Maume Jr, David J. 1999. "Occupational Segregation and the Career Mobility of White Men and Women." Social Forces 77(4): 1433-1459.

McPherson, Miller, Lynn Smith-Lovin and James Cook. 2001. "Birds of a Feather: Homophile in Social Networks." Annual Review of Sociology 27:415-444.

Moore, Gwen. 1988. "Women in Elite Positions: Outsiders Or Insiders?" Sociological Forum 3(4):566-585.

Morris, Altman. 2001. "Preferences and Labor Supply: Casting some Light into the Black Box of Income-Leisure Choice." Journal of Socio- Economics 33:199-219.

Padavic, Irenne A. 1992. "White-Collar Work Values and Women's Interest in Blue-Collar Jobs." Gender and Society 6(2): 215-230.

Percheski, Christine. 2008. "Opting Out? Cohort Differences in Professional Women's Employment Rates from 1960 to 2005." American Sociological Review 73(3):497-517.

Pettit, Becky and Jennifer L. Hook. 2009. Gendered Tradeoffs: Family, Social Policy, and Economic Inequality in Twenty-One Countries. New York: Russel Sage Foundation. 
Reskin, Barbara F. 1993. "Sex Segregation in the Workplace." Annual Review of Sociology 19:241-270.

Reskin, Barbara F. and Heidi I. Hartmann. 1986. Women's Work, Men's Work: Sex Segregation at Work. Washington D.C.: National Academy Press.

Reskin, Barbara F. and Catherine E. Ross. 1992. "Jobs, Authority and Earnings among Managers: The Continuing Significance of Sex." Work and Occupations 19(4):342-365.

Ridgeway, Cecilia L., Elisabeth H. Boyle, Kathy J. Kuipers and Dawn T. Robinson. 1998. "How do Status Beliefs Develop? The Role of Resources and Interactional Experience." American Sociological Review 63:331-50.

Rosenbaum, James E. 1985. "Jobs, Job Status and Women's Gains from Affirmative Action: Implications for Comparable Worth." Pp. 116-136 in Comparable Worth: New Directions for Research., edited by H.I. Hartmann. Washington D.C.: National Academy Press.

Ruhm, Chistopher J. 1991. “Are Workers Permanently Scarred by Job Displacement?" American Economic Review 81:319-324

Rydzewski, L.G., William Deming, and Philip Rones. 1993. "Seasonal employment falls over past three decades". Monthly Labor Review 116(7):3-5

Sorensen, Aage B. 1974. "A Model for Occupational Careers." American Journal of Sociology 80(1):44-57.

Sousa-Poza, Alfonso and Fred Henneberger. 2002. "An Empirical Analysis of Working Hours Constraints in Twenty-One Countries." Review of Social Economy 60:209-242. 
Spradley, James P. and Brenda J. Mann. 1975. The Cocktail Waitress: Woman's Work in a Man's World. New York: John Wiley.

Tam, Tony. 1997. "Sex Segregation and Occupational Gender Inequality in the United States: Devaluation or Specialized Training." American Journal of Sociology 102:1652-1692.

Taylor, Catherine J. 2010. "Occupational Sex Composition and the Gendered Availability of Workplace Support." Gender and Society 24:189-212.

Tomaskovic-Devei, Donald, Catherine Zimmer, Kevin Stainback, Corre Robinson, Tiffany Taylor and Tricia McTague. 2006. "Documenting Desegregation: Segregation in American Workplaces by Race, Ethnicity, and Sex, 1966-2003." American Sociological Review 71(4):565-588.

Tomaskovic-Devei, Donald. 1993. "The Gender and Race Composition of Jobs and the Male/Female, White/Black Gender Gaps." Social Forces 72(1):45-76.

Waite, Linda J. and Sue E. Berryman. 1985. Women in Nontraditional Occupations: Choice and Turnover. Santa Monica: Rand Corp. 
Table 1. Person-year, 1979-2006

\begin{tabular}{|c|c|c|}
\hline \multirow[b]{2}{*}{ Year } & \multicolumn{2}{|c|}{ Person-year } \\
\hline & $\begin{array}{c}\text { Professionals/ } \\
\text { Managers }\end{array}$ & $\begin{array}{c}\text { Non- } \\
\text { Professionals/ } \\
\text { Managers }\end{array}$ \\
\hline 1979 & 18 & 64 \\
\hline 1980 & 20 & 77 \\
\hline 1981 & 34 & 89 \\
\hline 1982 & 56 & 145 \\
\hline 1983 & 61 & 145 \\
\hline 1984 & 141 & 169 \\
\hline 1985 & 162 & 181 \\
\hline 1986 & 155 & 194 \\
\hline 1987 & 253 & 175 \\
\hline 1988 & 273 & 199 \\
\hline 1989 & 252 & 194 \\
\hline 1990 & 267 & 186 \\
\hline 1991 & 252 & 222 \\
\hline 1992 & 291 & 210 \\
\hline 1993 & 243 & 205 \\
\hline 1994 & 261 & 193 \\
\hline 1995 & 306 & 197 \\
\hline 1996 & 312 & 194 \\
\hline 1997 & 348 & 203 \\
\hline 1998 & 339 & 212 \\
\hline 1999 & 349 & 227 \\
\hline 2000 & 325 & 224 \\
\hline 2001 & 150 & 197 \\
\hline 2002 & 86 & 183 \\
\hline 2003 & 90 & 187 \\
\hline 2004 & 80 & 167 \\
\hline 2005 & 89 & 156 \\
\hline 2006 & 82 & 149 \\
\hline Total & 5,295 & 4,944 \\
\hline
\end{tabular}


Table 2. Descriptive statistics of predictors for women's attrition from male-dominated jobs.

\begin{tabular}{|c|c|c|c|c|c|c|}
\hline & \multicolumn{2}{|c|}{ Ever worked } & \multicolumn{2}{|c|}{$\begin{array}{c}\text { Ever worked in } \\
\text { a male- } \\
\text { dominated } \\
\text { occupation }\end{array}$} & \multicolumn{2}{|c|}{$\begin{array}{c}\text { Only worked in } \\
\text { male-dominated } \\
\text { occupations }\end{array}$} \\
\hline & Mean & S.D & Mean & S.D. & Mean & S.D. \\
\hline \multicolumn{7}{|l|}{ Socio-demographic variables } \\
\hline Some college/college degree & 0.013 & 0.116 & 0.015 & 0.121 & 0.191 & 0.393 \\
\hline Male-dominated major & 0.037 & 0.189 & 0.043 & 0.202 & 0.242 & 0.249 \\
\hline School attendance & 0.043 & 0.203 & 0.042 & 0.206 & 0.046 & 0.209 \\
\hline Married & 0.577 & 0.494 & 0.563 & 0.496 & 0.431 & 0.496 \\
\hline Marriage dissolution & 0.168 & 0.374 & 0.184 & 0.387 & 0.186 & 0.389 \\
\hline First born & 0.47 & 0.499 & 0.464 & 0.499 & 0.363 & 0.481 \\
\hline Second born & 0.299 & 0.458 & 0.293 & 0.455 & 0.309 & 0.462 \\
\hline Mother's age at first born & 0.655 & 0.475 & 0.648 & 0.477 & 0.720 & 0.449 \\
\hline \multicolumn{7}{|l|}{ Work-related variables } \\
\hline Full time employment & 0.75 & 0.433 & 0.762 & 0.426 & 0.791 & 0.408 \\
\hline High-paid managers & 0.015 & 0.123 & 0.022 & 0.148 & 0.071 & 0.258 \\
\hline Mid-paid managers & 0.037 & 0.188 & 0.052 & 0.223 & 0.142 & 0.35 \\
\hline Low-paid managers & 0.023 & 0.15 & 0.034 & 0.181 & 0.026 & 0.158 \\
\hline Professionals (not teachers) & 0.114 & 0.318 & 0.105 & 0.306 & 0.311 & 0.464 \\
\hline Teachers & 0.048 & 0.213 & 0.029 & 0.168 & 0.006 & 0.075 \\
\hline Service workers & 0.195 & 0.396 & 0.179 & 0.383 & 0.017 & 0.128 \\
\hline Sales workers & 0.076 & 0.274 & 85,00 & 0.278 & - & - \\
\hline Clerical workers & 0.219 & 0.414 & 0.204 & 0.403 & 0.020 & 0.140 \\
\hline Blue-collar workers & 0.261 & 0.419 & 0.273 & 0.446 & 0.360 & 0.480 \\
\hline \multicolumn{7}{|l|}{ Work trajectory } \\
\hline Work-leaves over the previous year & 0.118 & 0.323 & 0.12 & 0.325 & 0.063 & 0.243 \\
\hline Previous episodes male-dominated occ. & 0.261 & 0.427 & 0.379 & 0.469 & - & - \\
\hline Years out of the labor market & 0.203 & 0.374 & 0.197 & 0.372 & 0.050 & 0.180 \\
\hline Job spells & 0.547 & 0.319 & 0.56 & 0.315 & 0.437 & 0.403 \\
\hline Job tenure & 0.048 & 0.177 & 0.073 & 0.214 & 0.242 & 0.359 \\
\hline Age first joined the labor market & 20.70 & 27,34 & 20,57 & 25,19 & 23,86 & 32,64 \\
\hline Years of experience in the labor market & 0.474 & 0.306 & 0.475 & 0.304 & 0.441 & 0.356 \\
\hline $\mathrm{N}$ & 69400 & & 44162 & & 350 & \\
\hline
\end{tabular}


Table 3. Odds ratios for women's attrition from male-dominated jobs. Professionals and managerial workers in Yeart. 1979-2006.

Exits from male-dominated occupations

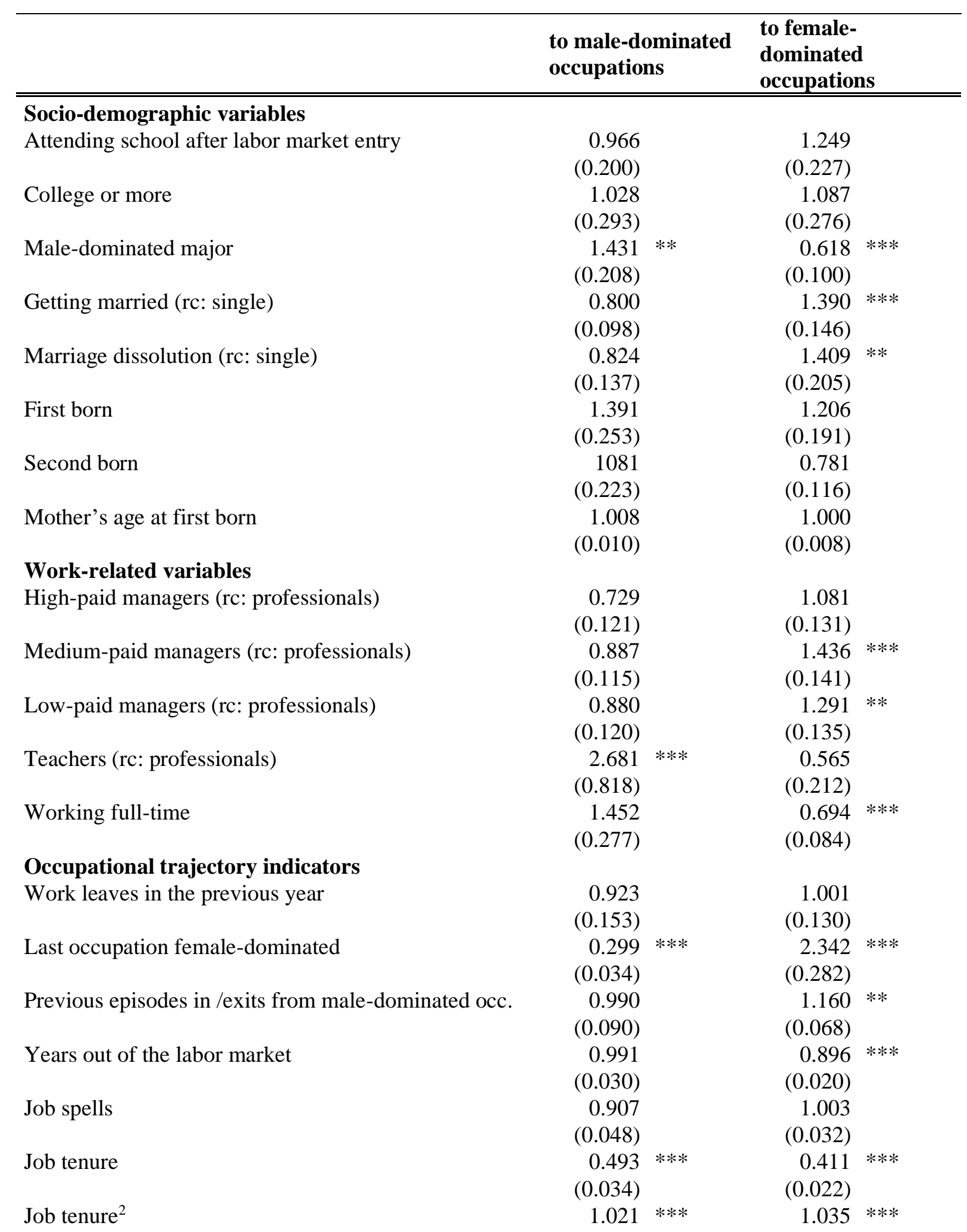


Age first joined the labor market

Years of experience in the labor market

$(0.026)$

$(0.021)$

0.979

1.022

$(0.017)$

$(0.015)$

Period 1990-2006

1.034

1.015

Constant

$(0.156)$

$(0.128)$

1.612

$4.624 * * *$

(1.094)

(2.481)

Events

565

1000

Pseudo $\mathrm{Chi}^{2}$

.18

.20

Numbers in parentheses are robust standard errors.

Individuals are clustered.

$* * * \mathrm{p}<0.01, * * \mathrm{p}<0.05$

Source: Calculated by the author from NLSY79 
Table 4. Odds ratios for women's attrition from male-dominated jobs. Service, clerical, sales and blue-collar workers in Yeart. 1979-2006

Exits from male-dominated occupations

\begin{tabular}{|c|c|c|c|c|}
\hline & \multicolumn{2}{|c|}{$\begin{array}{l}\text { to male-dominated } \\
\text { occupations }\end{array}$} & \multicolumn{2}{|c|}{$\begin{array}{l}\text { to female- } \\
\text { dominated } \\
\text { occupations }\end{array}$} \\
\hline \multicolumn{5}{|l|}{ Socio-demographic variables } \\
\hline \multirow[t]{2}{*}{ Attending school after entry in the labor market } & 1.119 & & 1.602 & \\
\hline & $(0.412)$ & & $(0.502)$ & \\
\hline \multirow[t]{2}{*}{ College or more } & 1.000 & & 0.206 & \\
\hline & $(0.000)$ & & $(0.215)$ & \\
\hline \multirow[t]{2}{*}{ Male-dominated major } & 1.325 & & 0.809 & \\
\hline & $(0.304)$ & & $(0.228)$ & \\
\hline \multirow[t]{2}{*}{ Getting married (rc: single) } & 1.011 & & 1.027 & \\
\hline & $(0.156)$ & & $(0.136)$ & \\
\hline \multirow[t]{2}{*}{ Marriage dissolution (rc: single) } & 1.357 & & 1.040 & \\
\hline & $(0.228)$ & & $(0.175)$ & \\
\hline \multirow[t]{2}{*}{ First born } & 0.984 & & 0.793 & \\
\hline & $(0.220)$ & & $(0.163)$ & \\
\hline \multirow[t]{2}{*}{ Second born } & 1.338 & & 0.924 & \\
\hline & $(0.254)$ & & $(0.162)$ & \\
\hline \multirow[t]{2}{*}{ Mother's age at first born } & 1.021 & $* *$ & 0.985 & \\
\hline & $(0.010)$ & & $(0.009)$ & \\
\hline \multicolumn{5}{|l|}{ Job-related variables } \\
\hline \multirow[t]{2}{*}{ Service (rc: blue-collar workers) } & 0.610 & $* * *$ & 1.840 & $* * *$ \\
\hline & $(0.115)$ & & $(0.272)$ & \\
\hline \multirow[t]{2}{*}{ Clerical (rc: blue-collar workers) } & 0.738 & & 1.221 & \\
\hline & $(0.159)$ & & $(0.229)$ & \\
\hline \multirow[t]{2}{*}{ Sales (rc: blue-collar workers) } & 0.362 & $* *$ & 1.664 & $* *$ \\
\hline & $(0.160)$ & & $(0.421)$ & \\
\hline \multirow[t]{2}{*}{ Working full-time } & 1.900 & $* * *$ & 0.653 & $* * *$ \\
\hline & $(0.297)$ & & $(0.079)$ & \\
\hline \multicolumn{5}{|l|}{ Occupational trajectory indicators } \\
\hline \multirow[t]{2}{*}{ Work leaves in the previous year } & 1.048 & & 0.936 & \\
\hline & $(0.153)$ & & $(0.135)$ & \\
\hline \multirow[t]{2}{*}{ Last occupation female-dominated } & 0.526 & $* * *$ & 1.614 & $* * *$ \\
\hline & $(0.058)$ & & $(0.201)$ & \\
\hline \multirow[t]{2}{*}{ Previous episodes in /exits from male-dominated occ. } & 1.062 & & 0.953 & \\
\hline & $(0.098)$ & & $(0.088)$ & \\
\hline \multirow[t]{2}{*}{ Years out of the labor market } & 0.922 & $* * *$ & 0.943 & \\
\hline & $(0.027)$ & & $(0.031)$ & \\
\hline \multirow[t]{2}{*}{ Job spells } & 0.965 & & 0.915 & $* * *$ \\
\hline & $(0.026)$ & & $(0.031)$ & \\
\hline \multirow[t]{2}{*}{ Job tenure } & 0.463 & $* * *$ & 0.387 & $* * *$ \\
\hline & $(0.033)$ & & $(0.030)$ & \\
\hline Job tenure ${ }^{2}$ & 1.033 & $* * *$ & 1.042 & $* * *$ \\
\hline
\end{tabular}




\begin{tabular}{|c|c|c|}
\hline \multirow{3}{*}{ Age first joined the labor market } & $(0.005)$ & $(0.006)$ \\
\hline & $0.922 * *$ & 1.039 \\
\hline & (0.031) & $(0.030)$ \\
\hline \multirow[t]{2}{*}{ Years of experience in the labor market } & 1.012 & 1.006 \\
\hline & $(0.018)$ & $(0.021)$ \\
\hline \multirow[t]{2}{*}{ Period 1990-2006 } & 1.137 & 1.070 \\
\hline & $(0.207)$ & $(0.181)$ \\
\hline \multirow[t]{2}{*}{ Constant } & 2.344 & 1.377 \\
\hline & (1.653) & $(0.866)$ \\
\hline Events & 720 & 755 \\
\hline Pseudo $\mathrm{Chi}^{2}$ & .16 & .19 \\
\hline \multicolumn{3}{|c|}{$\begin{array}{l}\text { Numbers in parentheses are robust standard errors. } \\
\text { Individuals are clustered. } \\
* * * \mathrm{p}<0.01, * * \mathrm{p}<0.05\end{array}$} \\
\hline
\end{tabular}


Figure 1. Event history model. Flux diagram 1979-2006

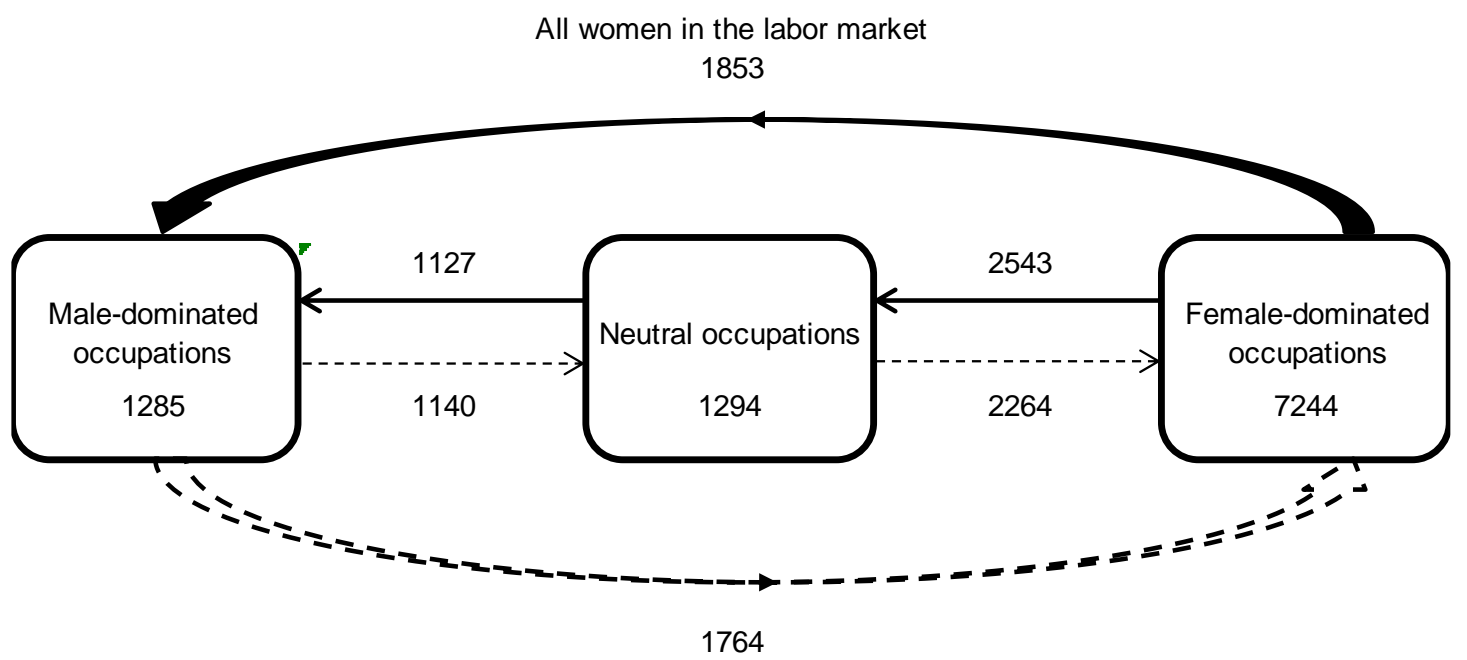

Professionals/Managers

172

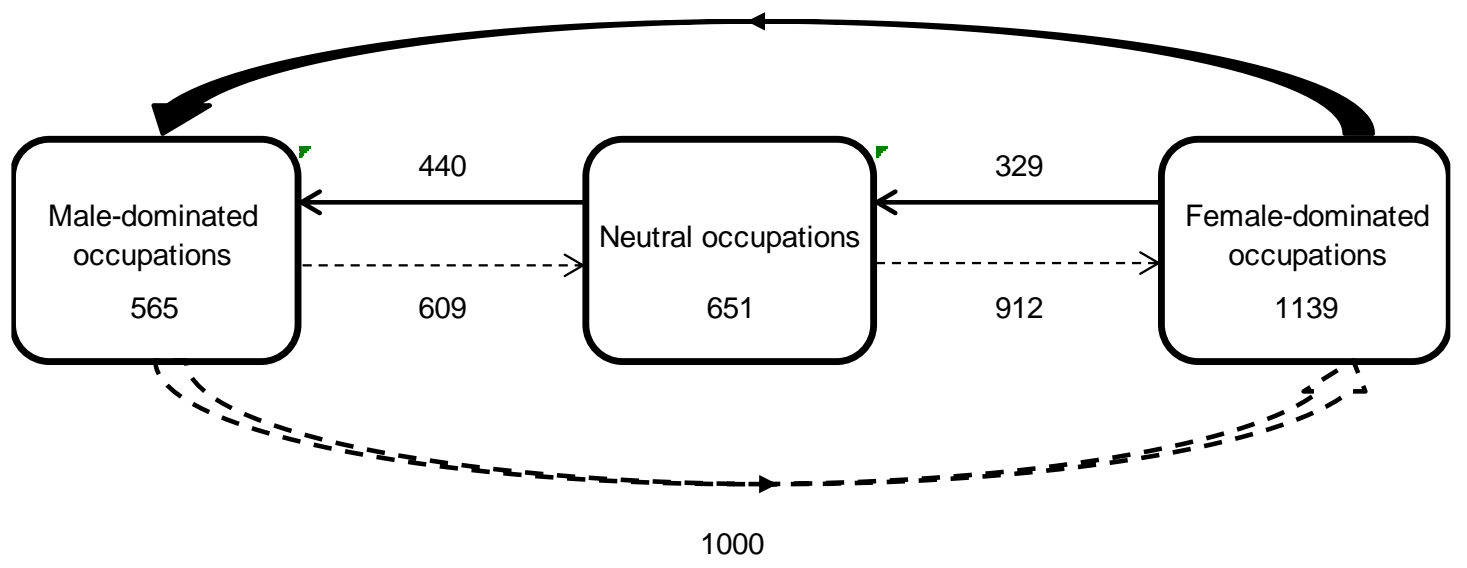

Non-professionals/managers

1681

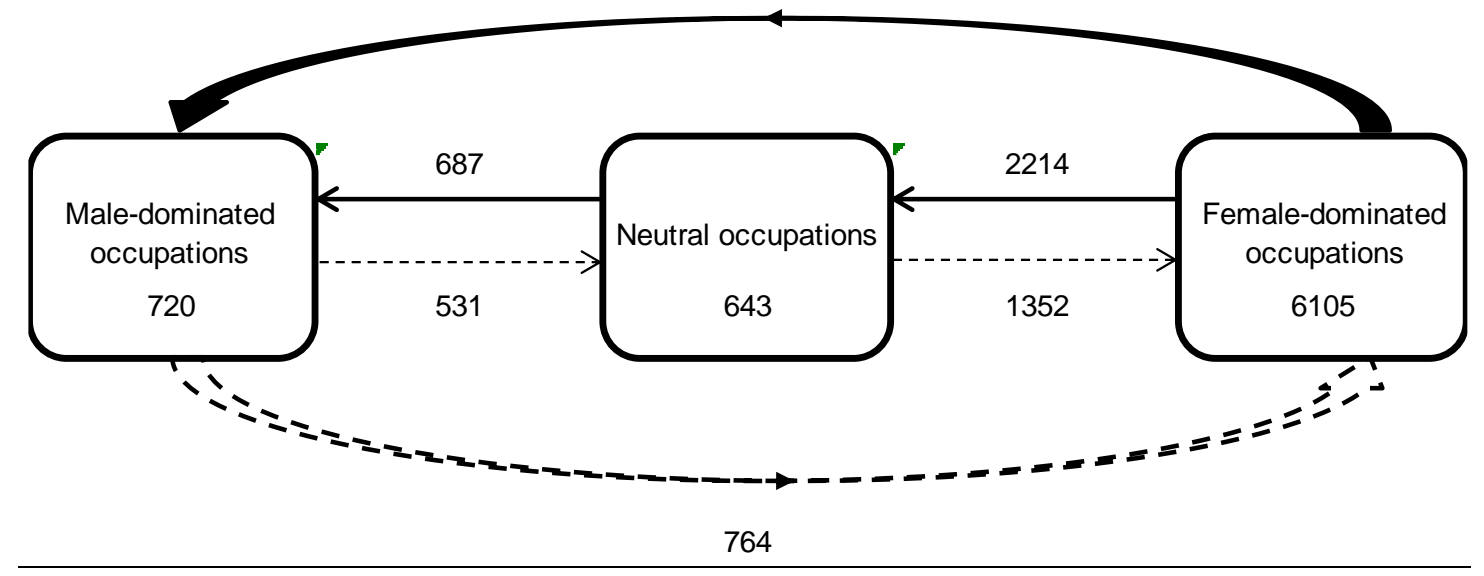

Source: Calculated by the author using NLSY79 
Figure 2. Probability of attrition from male- to female-dominated occupations. High- and low-status workers
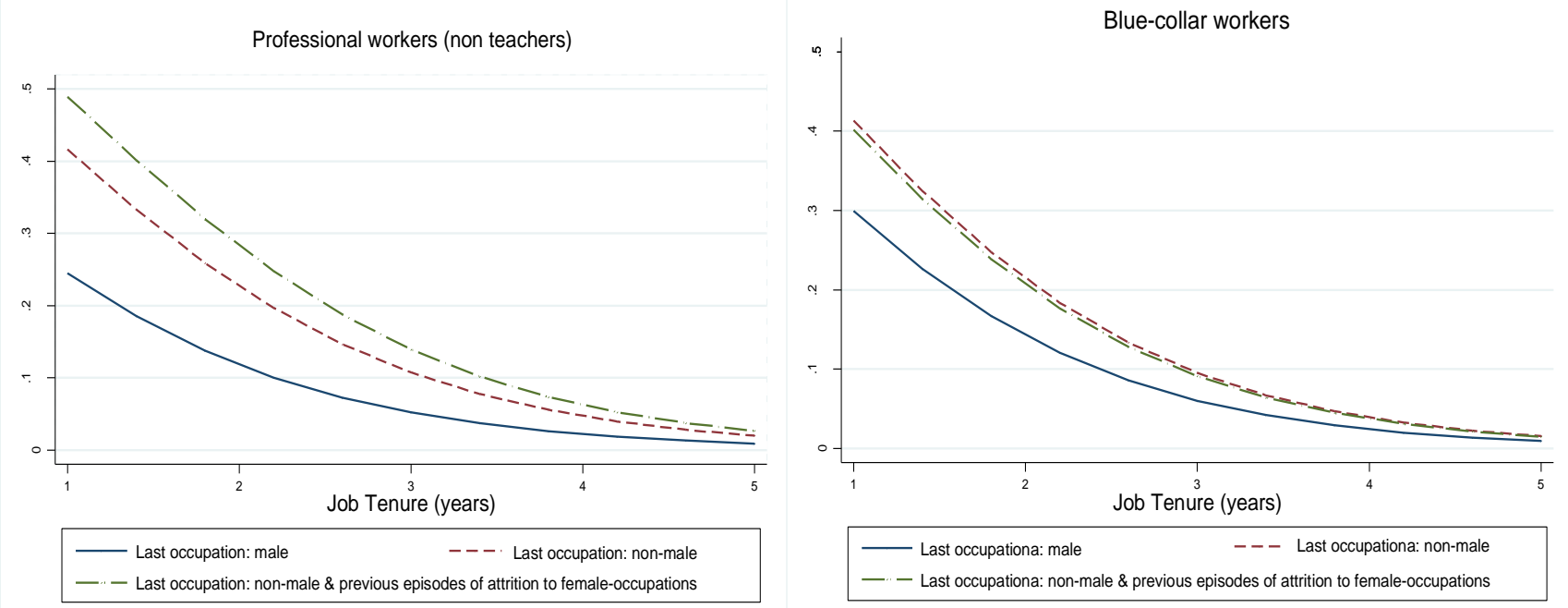

Source: Calculated by the author using NLSY79 